\title{
(Triphenylphosphine)gold(I) Chloride
}

\section{Annika C. J. Heinrich}

Otto-Diels Institute for Organic Chemistry, University of Kiel, Otto-Hahn-Platz 4 24098 Kiel, Germany

aheinrich@oc.uni-kiel.de

Published online: 01.04 .2015

DOI: 10.1055/s-0034-1380551; Art ID: st-2015-v0520-v

(Triphenylphosphine)gold(I) chloride, $\mathrm{ClAuPPh}_{3}$, is a well characterized colorless complex ${ }^{1}$ with a melting point of $236-240{ }^{\circ} \mathrm{C}^{2}$ and it is soluble in most common organic solvents. Although it is commercially available, it is cheaper to prepare it directly from elemental gold in an easy, highyielding two-step synthesis. In the first step, gold is dissolved in boiling aqua regia to form the gold(III) intermediate $\mathrm{AuCl}_{4}$ in solution. By adding dimethyl sulfide, the complex $\mathrm{ClAuSMe}_{2}$ precipitates as a white solid in an excellent yield of $93 \%{ }^{3}$

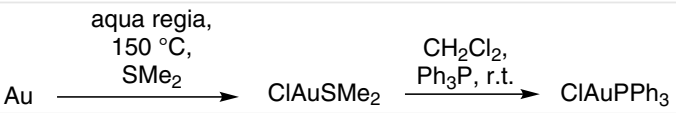

Scheme 1 Preparation of (triphenylphosphine)gold(I) chloride
Annika Heinrich studied chemistry at the University of Kiel and there she obtained her diploma degree in 2011. At the moment, she is working as a Ph.D. student in the group of Professor Dr. Anne Staubitz at the Institute of Organic Chemistry in Kiel. Her research focuses on highly selective cross-coupling reactions and on the synthesis of semiconducting polymers. (Triphenylphosphine)gold(I) chloride is a frequently used reagent in her research: It is used for the synthesis of aromatic organogold compounds that can be used in cross-coupling reactions and polymerization reactions.

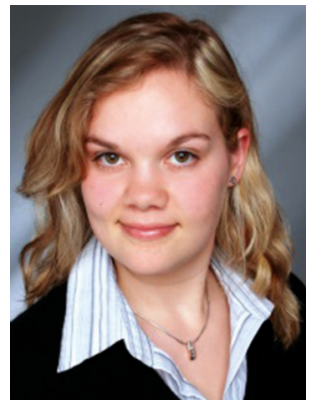

This precursor complex is dissolved in dichloromethane together with triphenylphosphine to form immediately the desired complex in a very good yield of $92 \%$ after precipitation by adding methanol. ${ }^{4} \mathrm{ClAuPPh}_{3}$ is a useful reagent in various types of reactions. It is often used in gold catalysis where it can act as co-catalyst or catalyst itself, or it can be used for the formation of more complex catalytic systems. ${ }^{5}$ $\mathrm{ClAuPPh}_{3}$ can also be used for the synthesis of organogold compounds, ${ }^{6}$ which can perform cross-coupling reactions in a generally mild manner and with high tolerance towards functional groups. Herein, some applications of $\mathrm{ClAuPPh}_{3}$ as reactant will be presented.

Table 1 Use of (Triphenylphosphine)gold(I) Chloride

(A) $\mathrm{ClAuPPh}_{3}$ can be used for the generation of gold nanoparticles. In the first step, gold chloride reacts with an ethylene glycol silver carboxylate in a transmetallation reaction. The resulting gold(I) complex generates the gold nanoparticle by thermal induction. The resulting nanoparticles do not need any further stabilizing or reducing reagents and have size diameters of 3-6 $\mathrm{nm}$ with narrow size distribution. ${ }^{?}$

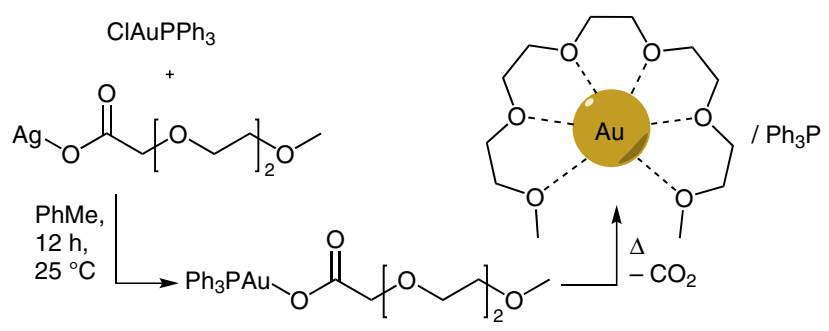

(B) Zhang et al. used $\mathrm{ClAuPPh}_{3}$ as catalytic species for the formation of various saturated substituted $\mathrm{O}$ - and $\mathrm{N}$-heterocycles. The homogeneous oxidative functionalization of terminal alkenes leads to a cyclization reaction that proceeds within short reaction times and under mild reaction conditions. In mechanistic studies they found that a conversion of $C\left(\mathrm{sp}^{3}\right)$-Au bonds into $\mathrm{C}\left(\mathrm{sp}^{3}\right)-\mathrm{C}\left(\mathrm{sp}^{2}\right)$ bonds is catalyzed by an $\mathrm{Au}(\mathrm{I}) / \mathrm{Au}(\mathrm{III})$ system in a cross-coupling manner when using boronic acids as nucleophiles with Selectfluor as oxidant. ${ }^{8}$

(C) Pérez-Sestelo and co-workers prepared different aryl-, alkynyl-, alkenyl-, and alkylgold(I) compounds in very high yields using the corresponding lithiated organic species and $\mathrm{ClAuPPh}_{3}$ as reagent. The organogold(I) compounds are used as nucleophiles in palladium-catalyzed cross-coupling reactions with various electrophiles under mild reaction conditions and in short reaction times. ${ }^{9}$

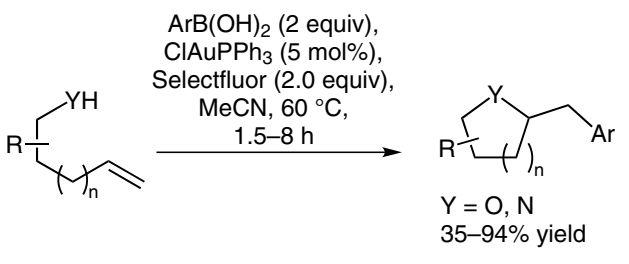

$\mathrm{ArB}(\mathrm{OH})_{2}$ (2 equiv), $\mathrm{ClAuPPh}_{3}(5 \mathrm{~mol} \%)$, lectfluor (2.0 equiv) $\mathrm{CN}, 60^{\circ} \mathrm{C}$ 35-94\% yield 
(D) Meyer et al. showed that trimethyltin-substituted naphthalene derivatives perform transmetalation reactions under very mild conditions using $\mathrm{ClAuPPh}_{3}$ as reagent. One example showed the synthesis of a compound containing both a gold(I) moiety and an iodide function on the same molecule, which cannot be prepared using organolithium or Grignard reagents in this case. ${ }^{10}$

(E) Rominger et al. used boronic acid derivatives as precursors for the synthesis of organogold(I) phosphane complexes. They are prepared in good yields of $82-98 \%$ using $\mathrm{ClAuPPh}_{3}$ as reagent. This method allows a higher tolerance towards functional groups than using lithiated species as reactants. As vinyl-, aryl- and heteroarylgold compounds are assumed to be intermediates in homogeneous gold catalysis, Rominger et al. used the prepared compounds to obtain more information about the mechanism of a catalytic cycle with gold. ${ }^{11}$

(F) Blum and co-workers prepared vinyl and aryl organogold(I) compounds by treating the corresponding vinyl- or arylmagnesium bromides with $\mathrm{ClAuPPh}_{3}$. These simple compounds were used for continuing steps of reactions: First they performed a regio- and diastereoselective palladium-catalyzed syn-carboauration of alkynes. In a further step, di- and trisubstituted olefins were synthesized by either performing palladium-catalyzed cross-coupling reactions or electrophilic trapping reactions. These reactions demonstrate the potential of the combination of gold and palladium in organic synthesis. ${ }^{12}$

(G) Keter et al. synthesized phosphinogold(I) dithiocarbamate complexes by using $\mathrm{ClAuPPh}_{3}$ and similar gold(I) precursors and different potassium salts of the corresponding dithiocarbamates under mild conditions and in short reaction times. The resulting complexes were tested for their activity against human cerival epithelioid carcinoma (HeLa) cells, a type of cancer. The P-Au-S moiety seemed to play an important role for the activity..$^{13}$

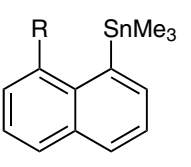

a) $\mathrm{R}=\mathrm{H}$

b) $R=1$ a) $\mathrm{ClAuPPh}_{3}$,

$\mathrm{PhMe}, 70^{\circ} \mathrm{C}, 2 \mathrm{~h}$

b) $\mathrm{ClAuPPh}_{3}$,

$\mathrm{CH}_{2} \mathrm{Cl}_{2}$, r.t., $2 \mathrm{~h}$<smiles>[R]c1cccc2cccc([C]([PH2+])[I+])c12</smiles>

a) $\mathrm{R}=\mathrm{H}(88 \%)$

b) $R=I(71 \%)$

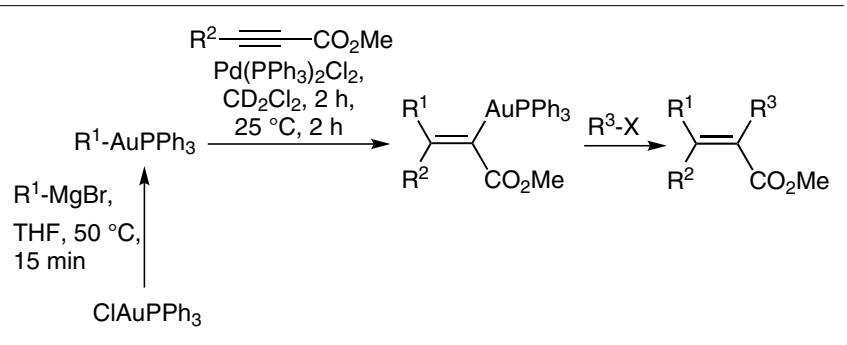

(1) Borissova, A. O.; Korlyukov, A. A.; Antipin, M. Y.; Lyssenko, K. A. J. Phys. Chem. A 2008, 112, 11519.

(2) Kouroulis, K. N.; Hadjikakou, S. K.; Kourkoumelis, N.; Kubicki, M.; Male, L.; Hursthouse, M.; Skoulika, S.; Metsios, A. K.; Tyurin, V. Y.; Dolganov, A. V.; Milaeva, E. R.; Hadjiliadis, N. Dalton Trans. 2009, 10446.

(3) Brandys, M.-C.; Jennings, M. C.; Puddephatt, R. J. Dalton Trans. 2000, 4601.

(4) Mézailles, N.; Ricard, L.; Gagosz, F. Org. Lett. 2005, 7, 4133.

(5) See for example: (a) Hashmi, A. S. K. Chem. Rev. 2007, 107, 3180. (b) Gorin, D. J.; Sherry, B. D.; Toste, F. D. Chem. Rev. 2008, 108, 3351. (c) Li, Z.; Brouwer, C.; He, C. Chem. Rev. 2008, 108, 3239.

(6) See for example: Liu, L.-P.; Hammond, G. B. Chem. Soc. Rev. 2012, 41, 3129.
(7) Tuchscherer, A.; Schaarschmidt, D.; Schulze, S.; Hietschold, M.; Lang, H. Inorg. Chem. Commun. 2011, 14, 676.

(8) Zhang, G.; Cui, L.; Wang, Y.; Zhang, L. J. Am. Chem. Soc. 2010, $132,1474$.

(9) Peña-López, M.; Ayán-Varela, M.; Sarandeses, L. A.; Pérez-Sestelo, J. Chem. Eur. J. 2010, 16, 9905.

(10) Meyer, N.; Sivanathan, S.; Mohr, F. J. Organomet. Chem. 2011, $696,1244$.

(11) Rominger, F.; Ramamurthi, T. D.; Hashmi, A. S. K. J. Organomet. Chem. 2009, 694, 592.

(12) Shi, Y.; Ramgren, S. D.; Blum, S. A. Organometallics 2009, 28, 1275.

(13) Keter, F. K.; Guzei, I. A.; Nell, M.; van Zyl, W. E.; Darkwa, J. Inorg. Chem. 2014, 53, 2058. 